\title{
Zika virus infections from the perspective of the general practitioner
}

MARIA GAŃCZAKA, E, F

Department of Epidemiology and Management, Pomeranian Medical University in Szczecin

A - Study Design, B - Data Collection, C - Statistical Analysis, D - Data Interpretation, E - Manuscript Preparation,

$\mathbf{F}$ - Literature Search, $\mathbf{G}$ - Funds Collection

Summary In February 2016, the World Health Organization declared the Zika virus (ZIKV) a global health emergency due to the rapid spread of this infection. ZIKV has been responsible for major outbreaks in Africa and Asia, and between 2013-2015, in previously infection-naive territories of the Pacific area, South and Central America. Poland is not considered an endemic territory regarding ZIKV due to low temperatures which limit the survival of the Aedes mosquito. However, imported cases are possible due to numerous international travel made by Poles to countries in which ZIKV vectors are present. Three Zika cases imported from the endemic countries to Italy, the US and Japan are discussed in the article - together with epidemiology, modes of transmission, clinical manifestations of ZIKV disease and diagnostic options - in the context of possible cases imported to Poland. The role a GP should play in the detection of ZIKV infections and in the rapid response to potential threats is also stressed. ZIKV infection represents both clinical and diagnostic challenges for GPs and other specialists, due to similar symptoms to other arboviral diseases and cross-reaction with other flaviviruses, which could lead to misdiagnosis. For a Polish doctor, the current epidemiological situation and clinical manifestation should be the main criteria to suggest ZIKV infection. Despite establishing diagnosis and treatment of imported ZIKV infections, a GP should be prepared for sharing information with patients who will travel to areas of the vector activity (especially pregnant women and those planning to become pregnant in the near future, as well as their partners) about the necessity to take precautions during and after their journey.

Key words: Zika virus, infection, clinical manifestation, diagnosis, prevention, GP.

Gańczak M. Zika virus infections from the perspective of the general practitioner. Fam Med Prim Care Rev 2016; 18(4): 487-491, doi: 10.5114/fmpcr.2016.63708.

\section{Background}

In the beginning of February 2016, the WHO declared the Zika virus (ZIKV) infection as a Public Health Emergency of International Concern due to the rapid increase in the number of new cases [1]. According to WHO estimates, ZIKV has infected 1.5 million people in the last few years. Since November 2016, there have been 71 countries reporting ZIKV infections; another 3-4 million could become infected this year $[1-3]$.

Recent expansion of ZIKV infection in various areas of the world highlights the potential for the pathogen to spread outside the Americas. ZIKV was first identified in Uganda, in a rhesus monkey from the Zika Forest (1947), and later in the Aedes africanus mosquito captured in the same jungle [4-6]. The first cases in humans were identified between 1952-1954 in Uganda and some other African countries [7]; serologic evidence of human ZIKV infection was then reported from countries located along the equatorial belt crossing Africa (Gabon, Sierra Leone, Central African Republic) and Asia (Indonesia, Thailand, India, the Philippines, Malaysia, Vietnam) $[6,8]$. Surveys indicate ZIKV circulation in various animal species (rodents and large mammals, such as elephants, hippos, artiodactyls, lions and monkeys) [9, 10].

The Aedes mosquito could transmit ZIKV to new hosts. In the 20th century, outbreaks caused by this pathogen were reported outside Africa and Asia - on islands from the Pacific region (Micronesia, French Polynesia), and countries in Central and South America (with widespread outbreaks reported in Brazil and Columbia: 440,000 - 1,300,000 and 30,000 reported cases, respectively), and Capo Verde [11].
Isolated cases, imported from endemic areas, have also been reported in Europe (Germany, France, Italy, the UK, Ireland, Denmark, Sweden, Spain, Austria, Finland), Israel, the US, Canada, Japan and Australia (Figure 1) [3, 10, 12-15].

The aim of this article is to discuss information currently available on ZIKV regarding the possibility of importing isolated cases to Poland, as well as the role family doctors should play in the case of detection and response to potential threats.

\section{Case studies of ZIKV infections}

Three clinical cases of ZIKV infections from Italy, Germany and the US are presented below, each being the first laboratory-confirmed case acquired in endemic areas and imported into the respective countries.

\section{Case 1}

In March 2015, a male Italian traveler in his 60s presented to the Infectious and Tropical Diseases Unit at one Italian hospital [12]. It was four days after his return from a 12-day holiday in Brazil. Upon returning to Italy, he presented a confluent pruritic erythematous rash on the face, torso, arms and legs, as well as conjunctivitis, weakness, painful edema of both hands and feet and a moderate fever $\left(38^{\circ} \mathrm{C}\right)$. Blood tests revealed thrombocytopenia and slightly elevated C-reactive protein, with a normal white blood cell count/ /differential count, serum transaminases and creatinine. Because of the clinical manifestation and the travel history to countries affected by Aedes mosquito, a viral infection was suspected. Patient serum was tested for antibodies against 


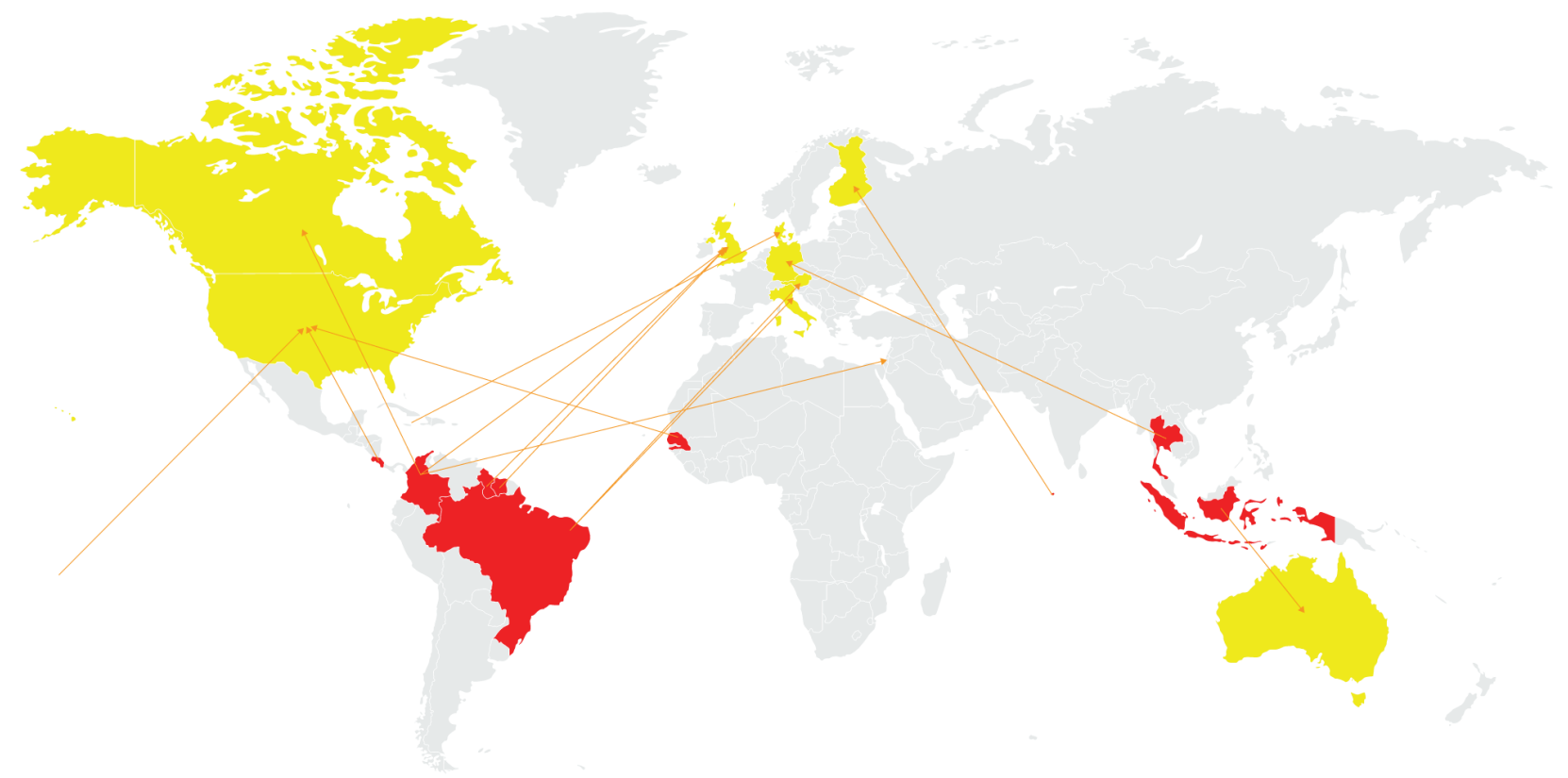

Figure 1. The global spread of Zika virus infections (in red), including imported cases [10, 12-15]

such viruses as: chikungunya (CHIKV), dengue (DENV), ZIKV, yellow fever (YFV), West Nile (WNV), Japanese encephalitis, Parvovirus B19, human herpes virus 6 (HHV6) and HIV. The serum sample showed a positive result for anti-ZIKV-IgM and IgG antibodies only, suggesting a ZIKV infection. The patient was discharged; symptomatic treatment with paracetamol was recommended. All symptoms resolved the following week, with a fever and rash lasting for only four days. A follow-up sample, taken 26 days after the onset of symptoms, showed a threefold increase of the antiZIKV-IgM and IgG antibody levels (ELISA). The presence of ZIKV-specific neutralizing antibodies was confirmed by a neutralization assay. Additionally, a low-titre DENV-IgG was observed, representing a possible serological crossreaction of anti-ZIKV-IgG antibodies. ZIKV-specific RT-PCR was negative from both samples.

\section{Case 2}

In December 2013, a 48-year-old male from New York City presented to the travel medicine clinic with an 11-day history of diffuse rash, fever, arthralgia, lower back pain, bilateral conjunctivitis and fatigue [13]. Five weeks prior to his illness, he had traveled to Ecuador, Peru, Bolivia, Chile, Easter Island, French Polynesia and Hawaii. During his travel to French Polynesia, the patient used repellents containing $30 \%$ DEET. Within 12 hours after departing the islands, he noted a pruritic erythematous rash on the posterior area of his neck, which progressed over the next days, together with fatigue, fever $\left(38.8^{\circ} \mathrm{C}\right)$, arthralgia, lower back pain and conjunctivitis. The patient used an over-the-counter analgesic and an antihistamine, which brought relief. By day 9, his symptoms resolved; however, a progression of the rash was observed. The day he presented to the outpatient clinic, he presented a diffuse maculopapular rash on his extremities and torso. Over the previous 20 years, he had a history of global travel, including visits to areas endemic for mosquitoborne infections, such as dengue, chikungunya, yellow fever and malaria. Additionally, he lived in an area endemic for WNV. He reported compliance with pre-travel health precautions, including a vaccination for yellow fever in 1999. Upon admission, laboratory tests did not show any abnormalities regarding a complete blood count with differential, serum electrolytes, as well as hepatic and renal profiles.
A sample on day 11 revealed positive anti-lgM and $\lg G$ titers for both DENV and WNV (ELISA); it also showed a negative result for ZIKV-IgM and positive ZIKV-IgG. RT-PCR testing could not be performed, as the patient presented himself to the clinic for evaluation on day 11 of his illness (laboratory protocol requires sample submission by day 10). A month after, the patient's symptoms had fully resolved with no abnormalities in physical examination. Serological tests were repeated. The sample revealed a positive ZIKV-IgM titer, as well as a fivefold increase in ZIKV-IgG titer. There was no significant change in the DENV and WNV-IgG titer.

\section{Case 3}

A Japanese woman in her 30s presented herself to the university hospital in Tokyo, Japan, in January 2014 after holidays in Bora Bora [14]. Despite the use of repellents, she reported several inflammatory papules on the skin after mosquito bites. The first symptoms occurred six days after her journey, which were retro-orbital pain and mild fever, followed by an itchy maculopapular rash on her face, torso and extremities and conjunctivitis three days later. Blood tests revealed leucopenia and thrombocytopenia. ZIKV-IgM antibodies were positive in two serum samples collected on the first day at the hospital and five days later (fourfold increase in the titer was observed); therefore, the patient was diagnosed with Zika fever. RT-PCR assay gave negative result for ZIKV RNA in serum, but the presence of the virus was detected in urine.

\section{Discussion}

\section{Epidemiological aspects of ZIKV infection}

ZIKV is transmitted to humans through the bite of an infected mosquito from the Aedes genus, which bites during the day $[1-3,6-14]$. Other Aedes species have been noted as vectors of ZIKV after the first report of Aedes albopictus as a potential vector of ZIKV. This may hint at a molecular evolution of the virus $[6,8]$. An increasing number of cases of this vector could have an influence on the appearance of new ZIKV epidemics globally, including Europe, with urban areas being at particular risk [15]. In the cases described above, all patients had histories of travel to regions 
affected by the Aedes mosquito (Brazil, French Polynesia), which focused diagnostic procedures on arboviral infections and enabled the establishment of a final diagnosis. Of note, patients reported multiple mosquito bites despite the use of repellents. There were also other cases of ZIKV infections reported in medical literature imported to non-endemic areas by tourists travelling to Thailand, Indonesia, French Polynesia, the Maldives, Senegal, Columbia, Surinam, Guadalupe and Tahiti [3, 16-18]. Since November 2016 there has been one confirmed travel-associated case of ZIKV infection reported in Poland and two possible cases (confirmatory tests in progress) in individuals who returned from endemic areas such as the Caribbean, South and Central America [19]. All travelers reported mosquito bites and demonstrated ZIKV infection symptoms.

\section{Clinical manifestation of ZIKV infections}

In all cases presented above, the incubation period was no longer than 12 days [12-14], which is in line with previous reports of ZIKV infections, i.e. 3-12 days [3, 10, 16-18]. Of note, the disease is usually asymptomatic ( $80 \%$ of cases). As presented above, symptomatic cases are characterized by a short-lasting, self-limiting febrile illness with a duration of 3-9 days without severe complications $[3,6,10-11,16-$ $-18]$. The symptoms observed are most frequently mild fever, arthralgia (small joints of the hands and feet), muscle ache, headache, retro-orbital pain, abdominal pain, prostration, edema, lymphadenopathy, non-purulent conjunctivitis and a maculopapular rash that can begin on the face and then spread throughout the body; gastro-intestinal signs, mainly vomiting, as well as prostatitis and hematospermia, can also be present (Figure 2) [3, 6, 8, 10, 16-18]. Symptoms are commonly misdiagnosed as dengue due to fever, headache and rash $[8,11]$.

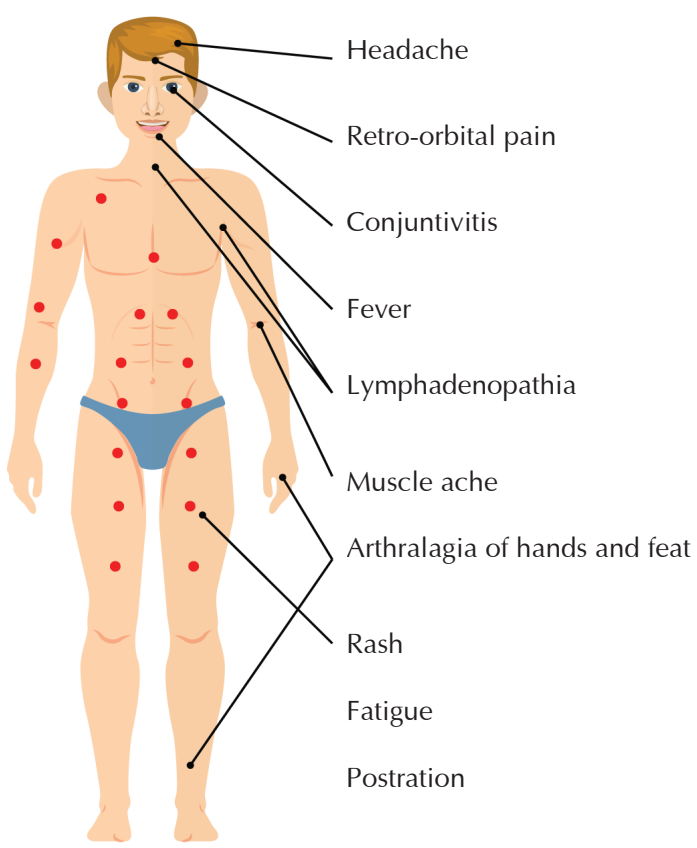

Figure 2. Symptoms of Zika virus infection

Some authors stress that non-purulent conjunctivitis, which is often presented in ZIKV infection (e.g. it was reported among 55\% cases in an outbreak on Yap Island, Micronesia [20], and was also presented by the patients described above), is rarely observed in the course of dengue.

In the cases presented above, the clinical manifestation was rather mild, and no complications were observed, although patients presenting with Guillain-Barré syndrome
(GBS) a few days upon clinical onset have been described in medical literature $[1-3,6,10,11,21,22]$. The triggering mechanism of this condition is still unknown, and an autoimmune process is likely to occur. No deaths have been reported in patients that developed GBS; however, some patients had to be admitted to ICUs. Recently, the association between ZIKV infection and GBS has been confirmed [23].

ZIKV has been found in the amniotic fluid and placenta, which points to possible mother-to-child transmission; other bodily fluids which are known to contain the virus are breast milk and the saliva of mothers and newborns [21, 22, 24]. Cases of microcephaly in fetuses and newborns among women suspected to have had Zika virus infection during the first and second trimester of pregnancy have been reported from ZIKV infection outbreaks [1-3, 6, 10, 22, 24]. A casual relationship between prenatal ZIKV infection and microcephaly and other brain anomalies has been found recently [25]. Computed tomography scans and transfontanellar cranial ultrasounds of infants born to women with suspected ZIKV infection during pregnancy showed a consistent pattern of widespread brain calcifications, mainly in the periventricular, parenchymal and thalamic areas, as well as in the basal ganglia. Ventricular enlargement secondary to cortical/subcortical atrophy was also frequently reported, which suggests acute intrauterine brain injury $[1-3,6,10$, $11,23,24]$. Current information about possible sexual transmission of ZIKV is based on case reports [26-28]. This was a probable sexual transmission of ZIKV from a husband to a wife, in which sexual contact occurred a few days before onset of the male symptoms [27]. High levels of ZIKV-RNA found in semen, as well as replicable ZIKV found in this bodily fluid at least 2 weeks after recovery, supports the hypothesis that it can be transmitted by sexual intercourse [3, 24-26]. ZIKV can be passed through sex (vaginal, anal, oral, and the sharing of sex toys), even if the person does not have symptoms at the time [28]. A theoretical possibility of transmission by transfusion exists based on the presence of the virus in $3 \%$ of asymptomatic Polynesian blood donors [11]. Such observations suggest that ZIKV could lead, in some cases, to disease even in the absence of vector-based transmission.

\section{Diagnostics of ZIKV infection}

Information on laboratory test results in the clinical course of ZIKV infection is rather scant. In the cases described above, patients had normal white blood cell count/ /differential count or leukopenia, normal platelet count, but also mild thrombocytopenia, slightly elevated C-protein levels, as well as normal hepatic and renal profiles. Previous investigators reported leukopenia, but not thrombocytopenia, in patients with ZIKV infection [12]. It is not known, so far, if transaminase levels could be helpful in differentiating between ZIKV infection and dengue fever. It has been noted that dengue fever has significantly elevated transaminase levels across the entire hospitalization, while the AST and ALT levels in ZIKV infection are within normal range. It has been reported recently that thrombocytopenia is a key parameter in differentiating between dengue and chikungunya [29]. However, in ZIKV infection, thrombocytopenia is likely to be present in many, but not all, described cases.

The diagnosis is based on the detection of specific ZIKV $\lg \mathrm{M} / \lg \mathrm{g}$ antibodies from blood samples through serological tests (ELISA or immunofluorescence) or the detection of the viral RNA genome from clinical specimens in acutely ill patients with the use of RT-PCR and virus isolation or the detection $[3,29-31]$. As the analysis of the clinical cases presented above shows, serological test results may be difficult to interpret, because the virus can cross-react with other flaviviruses (DENV, WNV, YFV) [29-31]. Interpretation of 
serological test results should be based on yellow fever vaccination status and previous exposure to any other flaviviral infections [10], which was also presented above. Additionally, the analysis of paired serum specimens, collected at different stages of the disease, is recommended, together with the detection of an increase in ZIKV antibody titer. It should be noted that since March 2016 serologic tests to detect ZIKV infection (IgM and/or IgG antibodies) have been available in Poland from the National Institute of Public Health (NIZP) [19]. The viraemic period of ZIKV infection appears to be short, allowing for direct virus detection during the first $3-5$ days after the onset of symptoms [13, 30, 31]. Therefore, as described in case 2, it is not recommended to perform the RT-PCR test 10 days after the onset of symptoms [13]. As described above, urine samples are also suitable for diagnosing ZIKV infection, as viral RNA is detectable in urine at a higher load than in serum up to 10 days after the onset of the disease [32].

A differential clinical diagnostic should be considered, as well as co-infection with other mosquito-borne diseases, such as dengue fever, chikungunya and malaria.

The analysis of cases described above shows that the management of ZIKV infections should be based on constant monitoring with symptomatic care. This should include fluid intake, fever reduction, pain relief and antihistamines for pruritic rash $[3,6,10]$. Acetylsalicylic acid and no-steroidal anti-inflammatory treatment drugs are not recommended due to the potential increased risk of hemorrhagic syndrome reported with other flaviviruses, as well as the risk of Reye's syndrome after viral infection in young patients [33]. There is no specific ZIKV antiviral treatment available; however, research to create a vaccine has been initiated $[3,6,10]$.

\section{Conclusions}

ZIKV is known to be spread by Aedes mosquitoes, which are not found throughout Poland, where the temperature is too low for them to survive. However, sporadic imported cases of infection have been reported in Polish citizens who have travelled to South and Central America and the Caribbean [19], where local ZIKV transmission has been observed. This also might be true for countries around the Mediterranean, Black Sea, Turkey, the Azores, the Canary Islands and Madera, which are well-travelled to by Poles and where arbovirus vectors are also present [3, 10, 34-36]. Another issue could be Polish sports competitors who will be participating in various global sports events, together with the fans who will be following them.
In the setting of family medicine, as well as in many other settings, ZIKV infection represents both a clinical and diagnostic challenge, since the symptoms are similar to other arboviral diseases and cross-reactive serology with other flaviviruses during ZIKV infection has been described, which may lead to incorrect diagnoses [1, 2, 12-14]. It should be pointed out that for a Polish doctor, a current epidemiological situation and clinical symptoms will be important criteria to diagnose ZIKV infection. Referral of suspected ZIKV cases to an infectious disease or tropical medicine specialist, more experienced at dealing with those infected with various flaviruses, is recommended. It is believed that it should be GP's duty to advise patients to take individual protective measures [31] when travelling to areas affected by ZIKV vectors.

Insect bite avoidance measures includes:

1) wearing long-sleeve shirts and long pants (preferably light-colored), especially during the hours of highest mosquito activity,

2) using insect repellent with at least 20\% DEET,

3) using permethrin to treat gear and clothing,

4) keeping doors and windows shut and using insect window/vent mesh screens,

5) remaining in air-conditioned areas,

6) using a bed net when sleeping,

7) reducing mosquito breeding sites through constant removal of containers, such as flower pots or buckets, as well as standing garbage, from courtyards and households $[3,6,10,31]$.

Special attention should be paid to pregnant women and those females who are planning to become pregnant, as well as young children and the elderly [1-3, 6, 10, 31]. Pregnant women (in any trimester) planning to travel to any regions currently experiencing the transmission of ZIKV should be advised to consider postponing their travel to those affected areas. Pregnant women should be also informed about the potential risk of sexual transmission of ZIKV from a partner returning from endemic areas [26]. In addition, male travellers returning from regions with ongoing transmission should be informed of the potential risk of sexual transmission and should consider using condoms or abstaining from sexual intercourse with their pregnant partners until after delivery. Travelers should be informed to contact their healthcare provider in case any symptoms compatible with ZIKV infection (as well as any other mosquito-borne diseases) emerge within three weeks after return from an affected area $[3,10]$.

Acknowledgments. The author wishes to acknowledge Marcel Gańczak for technical help regarding the figures.

Source of funding: This work was funded by the author's resources. Conflict of interest: The author declares no conflict of interests.

\section{References}

1. WHO statement on the first meeting of the International Health Regulations (2005) Emergency Committee on Zika virus and observed increase in neurological disorders and neonatal malformations [cited 8.02.2016]. Avaible from URL: http://www. who.int/ mediacentre/news/statements/2016/1 st-emergency-committee-zika/en/.

2. WHO Director-General summarizes the outcome of the Emergency Committee regarding clusters of microcephaly and Guillain-Barré syndrome [cited 8.02.2016]. Avaible from URL: http://www.who.int/mediacentre/news/statements/2016/emergency-committee-zika-microcephaly/en/.

3. European Centre for Disease Prevention and Control. Zika virus epidemic in the Americas: potential association with microcephaly and Guillain-Barré syndrome (first update) 21 January 2016. Stockholm: ECDC; 2016 [cited 21.01.2006]. Avaible from URL: http://ecdc.europa.eu/en/publications/Publications/rapid-risk-assessment-zika-virus-first-update-jan-2016.pdf.

4. Dick GW, Kitchen SF, Haddow AJ. Zika virus. I. Isolations and serological specificity. Trans R Soc Trop Med Hyg 1952; 46(5): 509-520.

5. Haddow AJ, Williams MC, Woodall JP, et al. Twelve isolations of Zika virus from Aedes (Stegomyia) africanus (Theobald) taken in and above a Uganda forest. Bull World Health Organ 1964; 31: 57-69.

6. Fauci AS, Morens DM. Zika virus in the Americas - yet another arbovirus threat. N Eng/ J Med; 2016; 374(7): 601-604.

7. Macnamara FN. Zika virus: a report on three cases of human infection during an epidemic of jaundice in Nigeria. Trans $R$ SoC Trop Med Hyg 1954; 48(2): 139-145. 
8. Hayes EB. Zika virus outside Africa. Emerg Infect Dis 2009; 15(9): 1347-1350.

9. Haddow AD, Schuh AJ, Yasuda CY, et al. Genetic characterization of Zika virus strains: geographic expansion of the Asian lineage. PLoS Negl Trop Dis 2012; 6(2): e1477.

10. European Centre for Disease Prevention and Control. Rapid risk assessment: Zika virus epidemic in the Americas: potential association with microcephaly and Guillain-Barré syndrome - 10 December 2015. Stockholm: ECDC; 2015 [cited 10.12.2015]. Avaible from URL: http://ecdc.europa.eu/en/publications/Publications/zika-virus-americas-association-with-microcephalyrapid-risk-assessment.pdf.

11. Musso D, Nilles EJ, Cao-Lormeau VM. Rapid spread of emerging Zika virus in the Pacific area. Clin Microbiol Infect 2014; 20(10): 595-596.

12. Zammarchi L, Tappe D, Fortuna C, et al. Zika virus infection in a traveler returning to Europe from Brazil, March 2015. Euro Surveill 2015; 20(23): pii: 21153.

13. Summers DJ, Acosta RW, Acosta AM. Zika virus in an American recreational traveler. J Travel Med 2015; 22(5): 338-340.

14. Kutsuna S, Kato Y, Takasaki T, et al. Two cases of Zika fever imported from French Polynesia to Japan, December 2013 to January 2014. Euro Surveill 2014; 19(4): pii: 2068.

15. loos S, Mallet HP, Leparc Goffart I, et al. Current Zika virus epidemiology and recent epidemics. Med Mal Infect 2014; 44(7): 302-307.

16. Fonseca K, Meatherall B, Zarra D, et al. First case of Zika virus infection in returning Canadian traveler. Am J Trop Med Hyg 2014; 91(5): 1035-1038.

17. Tappe D, Nachtigall S, Kapaun A, et al. Acute Zika virus infection after travel to Malaysian Borneo, September 2014. Emerg Infect Dis 2015; 21(5): 911-913.

18. Wæhre T, Maagard A, Tappe D, et al. Zika virus infection after travel to Tahiti, December 2013. Emerg Infect Dis 2014; 20(8): $1412-1414$

19. Narodowy Instytut Zdrowia Publicznego. Najważniejsze informacje na tema wirusa Zika [cited 25.11.2016]. Avaible from URL: http://www.pzh.gov.pl/zika/.

20. Duffy MR, Chen TH, Hancock WT, et al. Zika virus outbreak on Yap Island, Federated States of Micronesia. N Engl J Med 2009; 360: 2536-2543.

21. Besnard M, Lastčre S, Teissier A, et al. Evidence of perinatal transmission of Zika virus, French Polynesia, December 2013 and February 2014. Euro Surveill 2014; 19(3): pii: 20751.

22. Pinto Junior VL, Luz K, Parreira R, et al. Zika virus: a review to clinicians. Acta Med Port 2015; 28(6): $760-765$.

23. Cao-Lormeau VM, Blake A, Mons S, et al. Guillain-Barré Syndrome outbreak associated with Zika virus infection in French Polynesia: a case-control study. Lancet 2016; 287(10027): 1531-1539.

24. Schuler-Faccini L, Ribeiro EM, Feitosa IM, et al. Possible association between Zika virus infection and microcephaly - Brazil, 2015. MMWR Morb Mortal Wkly Rep 2016; 65(3): 59-62.

25. Rasmussen SA, Jamieson DJ, Honein MA, et al. Zika Virus and birth defects - reviewing the evidence for causality. $N$ Engl J Med 2016; 374(20): 1981-1987.

26. Musso D, Roche C, Robin E, et al. Potential sexual transmission of Zika virus. Emerg Infect Dis 2015; 21 (2): 359-361.

27. Foy BD, Kobylinski KC, Chilson Foy JL, et al. Probable non-vector-borne transmission of Zika virus, Colorado, USA. Emerg Infect Dis 2011; 17(5): 880-882.

28. Petersen EE, Meaney-Delman D, Neblett-Fanfair R, et al. Update: Interim guidance for preconception counseling and prevention of sexual transmission of Zika virus for persons with possible Zika virus exposure - United States, September 2016. Morb Mortal Wkly Rep 2016; 65(39): 1077-1081.

29. Lee VJ, Chow A, Zheng X, et al. Simple clinical and laboratory predictors of Chikungunya versus dengue infections in adults. PLoS Negl Trop Dis 2012; 6(9): e1786.

30. Marano G, Pupella S, Vaglio S, et al. Zika virus and the never-ending story of emerging pathogens and transfusion medicine. Blood Transfus 2015; 14(2): 95-100.

31. Balm MN, Lee CK, Lee HK, et al. A diagnostic polymerase chain reaction assay for Zika virus. J Med Virol 2012; 84(9): 1501-1505.

32. Gourinat A-C, $\mathrm{O}^{\prime}$ Connor O, Calvez E, et al. Detection of Zika virus in urine. Emerg Infect Dis 2015; 21(1): 84-86.

33. European Centre for Disease Prevention and Control. Zika virus infection (Factsheet for health professionals). Stockholm: ECDC; 2015 [cited 27.11.2015]. Avaible from URL: http://ecdc.europa.eu/en/healthtopics/zika_virus_infection/factsheethealth-professionals/Pages/factsheet_health_professionals.aspx.

34. Charakterystyka podróży krajowych i zagranicznych mieszkańców Polski w I półroczu 2015 r. [cyt. 1.02.2016]. Dostępny na URL: http://www.msport.gov.pl/statystyka-turystyka/charakterystyka-krajowych-i-zagranicznych-podrozy-mieszkancowpolski-w-i-polroczu-2015-roku.

35. Zammarchi L, Stella G, Mantella A, et al. Zika virus infections imported to Italy: clinical, immunological and virological findings, and public health implications. J Clin Virol 2015; 63: 32-35.

36. Kacprzak E, Mrówka K, Stefaniak J. Jak przygotować pacjenta do wyjazdu do krajów strefy tropikalnej? Fam Med Prim Care Rev 2009; 11(3): 347-351.

Tables: 0

Figures: 2

References: 36

Received: 12.02 .2016

Revised: 21.02 .2016

Accepted: 02.03.2016

Address for correspondence:

Maria Gańczak, MD, PhD, Assoc. Prof.

Zakład Epidemiologii i Zarządzania

Wydział Nauk o Zdrowiu PUM

ul. Żołnierska 48, 71-210 Szczecin

Polska

Tel.: +48 91 48-00-995, 965

E-mail:mganczak@pum.edu.pl 